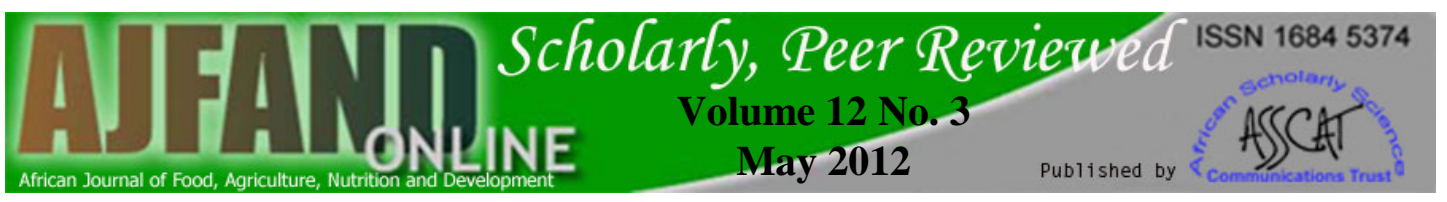

\title{
SCREENING OF PLANT GROWTH-PROMOTING RHIZOBACTERIA FROM MAIZE (ZEA MAYS) AND WHEAT (TRITICUM AESTIVUM)
}

\section{Karnwal A ${ }^{* 1}$}

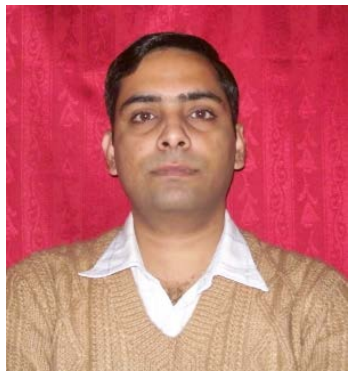

Arun Karnwal

*Corresponding Author: arunkarnwal@gmail.com

${ }^{1}$ Reader, Bhojia Institute of Life Sciences, Teh. Nalagarh, Budh, Baddi, Solan, H.P. 173205. 


\section{ABSTRACT}

Plant growth-promoting rhizobacteria (PGPR) are free-living soil-borne bacteria that colonize the rhizosphere and have great importance in governing the functional property of terrestrial ecosystems. In this study, rhizospheric bacteria were isolated from maize and wheat and screened for their plant growth promoting activities. These isolates were identified as Pseudomonas, Bacillus, Azospirillum and Azotobacter species. All isolates were tested for their indole acetic acid (IAA) production ability. All isolates produce the varying amounts of IAA ranging from $0.6-2.7 \mu \mathrm{g} / \mathrm{ml}$. The highest concentration of IAA was produced by bacterial strain Bacillus subtilis AK31. A series of growth pouch and pot experiments were conducted to study the effect of bacterial inoculants on the growth of maize and wheat. It was concluded that IAA plays a key role in the growth promotion of roots in maize and wheat in growth pouch study. In maize, isolate AK1, AK21, AK31 and AK8 showed high indole acetic acid (6.86, 7.11, 7.11 and $7.36 \mathrm{pmol} / \mathrm{ml}$, respectively) and root elongation activity (4.10, $5.00,5.00$ and $3.80 \mathrm{~cm}$, respectively) after $96 \mathrm{~h}$ of growth. In wheat, bacterial strains AK31, AK2, AK14, AK32 and AK15 showed high IAA (6.59, 5.66, 5.35, 7.53 and $5.66 \mathrm{pmol} / \mathrm{ml}$, respectively) and root elongation (6.07, 4.00, 5.20, 6.90 and $5.20 \mathrm{~cm}$, respectively) activity after $96 \mathrm{~h}$ of growth. In pot experiments, Bacillus sp. AK21, Bacillus subtilis AK31, Azotobacter diazotrophicus AK14, Microbacterium sp. AK19 and Pseudomonas fluorescens AK32 showed effective results in terms of increase in root and shoot dry weight in maize $(123,130,121,120,124 \mathrm{~g}$ and 116, 126, 116, 114, $120 \mathrm{~g} / \mathrm{pot}$, respectively) and wheat $(130,135,125,118,140 \mathrm{~g}$ and 105, 106, 110, 102, $110 \mathrm{~g} / \mathrm{pot}$, respectively), in comparison to controls of maize and wheat crops. Thus, it might be concluded that PGPR strains AK21, AK31, AK14, AK19 and AK32 could be used as crop-enhancer and bio-fertilizer for production of maize and wheat.

Key words: Gnotobiotic assay, Maize, Wheat, Phytohormones 


\section{INTRODUCTION}

Soil contains a wide diversity of microbes. Microbes are concentrated in nutrient-rich soil regions, including the topsoil layer and the region around the plant root. Roots secrete rhizodeposits that stimulate microbial life and allow fast spreading of microbes through soils. Plants can benefit from soil microbes in many ways. Certain microbes stimulate plant growth, enrich soils, degrade pollutants, or protect plants against pathogens. Analysis of the genotypic and phenotypic characteristics of indigenous rhizobacteria can help in understanding the mechanism of interactions between them and plant roots [1]. Plant growth-promoting rhizobacteria (PGPR) are free-living, soil-borne bacteria, which, when applied to seeds or crops, enhance the growth of the plant or reduce the damage from soil-borne plant pathogens [2]. The rhizosphere is the soil portion found around the root and under the influence of the root. It is the site with complex interaction between the root and associated microorganisms [3]. It has been noted by many workers that Pseudomonas, Bacillus, Arthrobacter, Azospirillum, Klebsiella, and Enterobacter, isolated from the rhizosphere of various crops, showed synergistic effects on plant growth $[2,4,5]$. Beneficial effects of micro-organisms have often been evaluated based on faster seed germination, better seedling emergence, and increased plant growth. Plant growthpromoting rhizobacteria enhance plant growth either by direct or indirect mechanisms [5]. The indirect mechanisms of plant growth promotion by PGPR include i) antibiotic production ii) depletion of iron from the rhizosphere iii) synthesis of antifungal metabolites iv) production of fungal cell wall lysing enzymes v) competition for sites on roots and vi) induced systemic resistance [2, 6, 7]. The production of phytohormones has been suggested to be one of the mechanisms by which PGPR bacteria stimulate plant growth [4]. Aslantas et al. [8] reported that the PGPR of apple showed the growth-promoting effect with possible involvement of the plant growth regulators indole-3-acetic acid and cytokinin. The objectives of the study were to isolate plant growth promoting rhizosphere bacteria from maize and wheat, and evaluate their beneficial effects on plant growth properties.

\section{METHODS}

\section{Pot experiments}

Soil was collected from Forest Research Institute, Dehradun. This soil had $\mathrm{pH} 6.7$ and contained $7.3 \mathrm{~g} / \mathrm{kg}$ organic C, $590 \mathrm{mg} / \mathrm{kg} \mathrm{N}, 60 \mathrm{mg} / \mathrm{kg}$ P, and $71 \mathrm{mg} / \mathrm{kg} \mathrm{K}$. Kjeldahl method was used to determine the total nitrogen content in the soil. For determination of the total organic carbon content, elementary analysis was used [9], while K and P content were also determined by flame photometric method and molybdenum blue method, respectively [10, 11]. For pot experiments, maize (Zea mays) and wheat (Triticum aestivum) were used as experimental plants.

\section{Isolation and characterization of soil microorganisms}

For the isolation of bacterial population, both maize and wheat plants were grown in the field. Plants were harvested 30 days after seed emergence were harvested. After harvesting, the roots and shoots were separated. To isolate the rhizospheric bacteria, loosely held soil to fresh roots were gently shaken with $9 \mathrm{ml}$ of sterile distilled water 
containing $1 \mathrm{ml}$ of $40 \%$ tetramethylthiuramdisulphide solution for $30 \mathrm{~min}$. From the suspension, a serial dilution (1:100) was prepared, and the resulting suspensions were spread over the surface of a succinate agar medium (sodium glutamate $1.00 \mathrm{~g}$, sodium succinate $5.00 \mathrm{~g}$, ammonium sulphate $0.40 \mathrm{~g}$, magnesium sulphate $0.20 \mathrm{~g}$, dipotassium hydrogen sulphate $0.50 \mathrm{~g}$, agar agar $15.0 \mathrm{~g}$ ). Six inoculated plates per dilution were incubated at $28^{\circ} \mathrm{C}$ and the bacterial colony forming units (CFUs) were counted after 72 hours of incubation. After getting the pure culture of isolated bacterial population, identification and characterization was done by using morphological, physiological, Biochemical and bacterial detection kit methods (BIOCON INC., INDIA).

\section{IAA production}

After the confirmation of IAA production activity by isolated bacterial isolates, bacterial strains were grown in succinate broth with and without tryptophan (500 $\mathrm{mg} / \mathrm{ml}$ ) and incubated at $28^{\circ} \mathrm{C}$ for 72 hours. A $2 \mathrm{ml}$ culture was taken from each tube and centrifuged at 10,000 rpm for 15 min (REMI RM-12C DX). One milliliter of the supernatant was taken in a tube to which $100 \mathrm{ml}$ of $10 \mathrm{mM}$ orthophosphoric acid and $2 \mathrm{ml}$ of reagent $\left(1 \mathrm{ml}\right.$ of $0.5 \mathrm{M} \mathrm{FeCl}_{3}$ in $50 \mathrm{ml}$ of $35 \% \mathrm{HClO}_{4}$ ) were added. After 25 minutes (after color density reached its maximum), the mixture was read in UVspectrophotometer at 530nm absorbance. The quantity of IAA was determined by comparison with a standard curve using pure IAA [12].

\section{Gnotobiotic assay of Growth Pouch Study (GPS)}

The gnotobiotic assay was performed as described by Lifshitz et al. [13]. Seeds were surface-sterilized by treatment with $95 \%$ ethanol (v/v) for 10 to $20 \mathrm{~s}$, followed by soaking in $20 \%$ bleach (v/v) for 10 min. Seeds were washed with sterile distilled water 5-7 times in order to remove excess bleach. The seeds were then air dried by placing them in the laminar flow hood for $24 \mathrm{~h}$. Surface-sterilized seeds were picked at random and placed onto half- strength tryptic soy agar (TSA) plates and incubated at $27^{\circ} \mathrm{C}$ for $24 \mathrm{~h}$ to further check for any contamination. Seeds were considered to be free from contamination if there were neither bacterial nor fungal growth occurring on plates incubated with surface-sterilized seeds.

A 100-fold dilution of the bacterial cells grown in half strength tryptic soy broth (TSB) was performed using $0.1 \mathrm{M} \mathrm{MgSO}_{4}$. Surface-sterilized seeds were soaked in $10 \mathrm{ml}$ of bacterial suspension for 10-15 min with gentle agitation.

Growth pouch experiments were conducted in order to determine the ability of PGPR strains to produce the phytohormone, indole-3-acetic acid (IAA) in the presence of maize and wheat roots. The effect of PGPRs (plant growth promoting rhizobacteria) inoculation on maize and wheat (individually) and the concentration of IAA in the rhizosphere were measured at different time intervals $(24 \mathrm{~h}, 48 \mathrm{~h}, 72 \mathrm{~h}$ and 96h). The growth pouches were filled with $25 \mathrm{ml}$ of Hoagland's nutrient solution and seeds treated with bacterial strains (maize and wheat, individually) were transferred aseptically to growth pouches (3 seeds per pouch and 3 pouches per treatment) [14]. Seeds treated with $0.1 \mathrm{M} \mathrm{MgSO}_{4}$ were considered as controls. The growth pouches were incubated in a growth cabinet with gentle shaking at $100 \mathrm{rpm}$ to create aerobic 
conditions for growth of PGPR strains. Supernatants from growth pouches $(10 \mathrm{ml})$ were obtained by centrifugation at $4000 \mathrm{rpm}$ for $20 \mathrm{~min}$ at $4^{\circ} \mathrm{C}$ (REMI RM-12C DX) and filtration using $0.22 \mu \mathrm{m}$ membrane filters. The phytohormone IAA was assayed using ELISA kits (Phytodetek, Agdia Inc, Elkhart, IN, USA). Stock solutions of the IAA $(10 \mu \mathrm{mole} / \mathrm{ml})$ were prepared in absolute methanol. Standard concentrations of 78-2500 pmoles/ml (IAA) were used. One hundred microlitres of standard or the sample were used for each assay.

The intensity of the color was read at 405nm using an ELISA plate reader and related to phytohormone concentrations by means of a standard curve.

\section{Plant growth promotion}

The effect of isolated strains on plant growth was studied in pot experiments. The inoculation treatments were setup in a randomized design with six replicates.

The day before sowing, pots were filled with $350 \mathrm{~g}$ soil. The soil was moistened with water and maintained at $60 \%$ of its moisture holding capacity. Four seeds of maize and 4 of wheat were sown per pot. After germination, plants were thinned to two per pot. The bacteria were cultured in glycerin-peptone-medium. Tubes were secured on a rotary shaker on $120 \mathrm{rpm}$ for 72 hours at $23^{\circ} \mathrm{C}$. Seedlings of these plants were inoculated with $1 \mathrm{ml}$ of the bacterial suspension, which resulted in an inoculum's density of $10^{6} \mathrm{cfu} / \mathrm{ml}$. The control was considered as un-inoculated plants. Plants were placed in a temperature-regulated growth chamber at a light intensity 20 kLux for 16 hours at $16^{\circ} \mathrm{C}$ during the day and $12^{\circ} \mathrm{C}$ at night.

\section{Data analysis}

The data were analysed for significant differences $(\mathrm{P}<0.05)$ of main effects using $2-$ way ANOVA and Student-Newman-Keuls tests.

\section{RESULTS}

All sixty isolates were screened for their PGPR activities and fifteen of them were selected for further studies due to their higher IAA production ability than the rest of isolates. Among the isolates, the representative bacterial strains in the rhizosphere were identified as Bacillus lentus AK1, Bacillus sp. AK21, Azospirillum brasilense AK11, Bacillus subtilis AK31, Bacillus lentus AK8, Bacillus sp. AK2, Pseudomonas fluorescens AK30, Azotobacter diazotrophicus AK14, Microbacterium sp. AK19, Bacillus lentus AK17, Pseudomonas fluorescens AK32, Bacillus sp. AK3 and Bacillus halodurans AK15.

All 15 bacterial strains produced IAA (Table 3). The highest concentration of IAA was produced by bacterial strain Bacillus subtilis AK31, Pseudomonas fluorescens AK32 and Bacillus sp. AK21.

Gnotobiotic assay or growth pouch study (GPS) with maize revealed that with control experiment less amount of IAA production were recorded $(0.15,0.99,1.51$ and 2.43 $\mathrm{pmol} / \mathrm{ml}$ at 24h, 48h, 72h and 96h, respectively), while PGPR inoculated seeds 
showed a good level of IAA production at different time intervals (Table 1). Similar results were also recorded with wheat seeds (Table 2). Furthermore, control experiments also revealed a deficient level of seed germination and radical length in maize $(0.1,0.4,1.1$ and $2.0 \mathrm{~cm})$ and wheat $(0.0,0.2,0.9$ and $1.8 \mathrm{~cm})$ at different time intervals (24h, 48h, $72 \mathrm{~h}$ and $96 \mathrm{~h})$ and good germination ability as well as increased root length were recorded in maize and wheat (Tables 1 and 2) with bacterial inoculated seeds. These results may provide partial evidence that PGPRs and IAA play an important role in plant growth promotion.

Results of pot experiments showed that the bacterial strains increased the root dry weight and shoot dry weight of maize (30\% and 26\%) and wheat (40\% and 10\%) as compared to the control (Table 4).

\section{DISCUSSION}

Plant growth-promoting rhizobacteria colonize plant roots and exert beneficial effects on plant growth and development by a wide variety of mechanisms. To be an effective PGPR, bacteria must be able to colonize root environment because they need to establish themselves in the rhizosphere at population densities sufficient to produce the beneficial effects. Our results have demonstrated that selected plant growthstimulating rhizosphere bacterial isolates were able to increase the growth of maize and wheat. Plant growth-promoting rhizobacteria promote plant growth by producing plant growth regulators or phytohormones [5]. These promote seed germination, root elongation, and stimulation of leaf expansion. Eighty percent of microorganisms, including pseudomonads, isolated from the rhizosphere of various crops have the ability to produce auxins as secondary metabolites $[15,16]$. Researchers showed that root surface area of maize seedlings was significantly increased after inoculation with Azospirillum [17, 18, 19, 20, 21, 22]. Similar results revealed that Pseudomonas inoculation (P. fluorescens PsIA12 and Agrobacterium rhizogenes A1A4) stimulated wheat growth [23, 24].

Many scientists reported that plant growth promoting rhizobacteria might enhance plant height and productivity by synthesizing phytohormones [25, 26, 27]. In our experiments, all selected bacterial strains were able to produced IAA at different concentrations in comparison to controls. In summary, the bacteria-associated plant growth properties shown in our experiments suggested that PGPR bacteria were able to produce phytohormone auxin (IAA) that stimulated the growth of maize and wheat crops.

It was hypothesized that IAA and other plant hormones were responsible for increased growth of canola, tomato and wheat in non-sterile soil inoculated with Azotobacter paspali [28]. The experiment carried out in present work has demonstrated that Plant growth-promoting isolates have capacity to modify the growth of maize and wheat. Auxins produced by rhizobacteria can influence plant growth, including root development which improve uptake of essential nutrients thus increasing plant growth [29]. In the pot experiment, it was observed that inoculation with PGPR strains significantly promoted growth and increased the root-shoot dry weight of maize and 


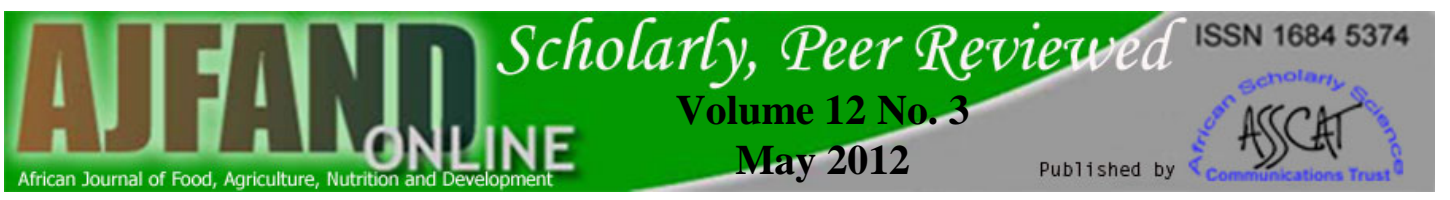

wheat. These results are consistent with the findings of other researchers who assessed the inoculation effect of PGPR Azospirillum brasilense on growth and dry weight of spring wheat $[18,30]$. Similarly, promotion in growth parameters and yields of various crop plants in response to inoculation with PGPR were reported by other workers [19, 20, 21, 27].

\section{CONCLUSION}

The greater root and shoot dry weight response to all inoculants compared to control clearly showed the beneficial role of these rhizobacteria. Such an improvement might be attributed to produce growth promoting substances. Based on these results, it can be concluded that, inoculation of Bacillus lentus, Bacillus sp., Azospirillum brasilense, Bacillus subtilis, Pseudomonas fluorescens, Azotobacter diazotrophicus, Bacillus halodurans and Pseudomonas strains as biofertilizer will be useful in increasing cereal productivity and contribute to tackling food deficits in the world. 


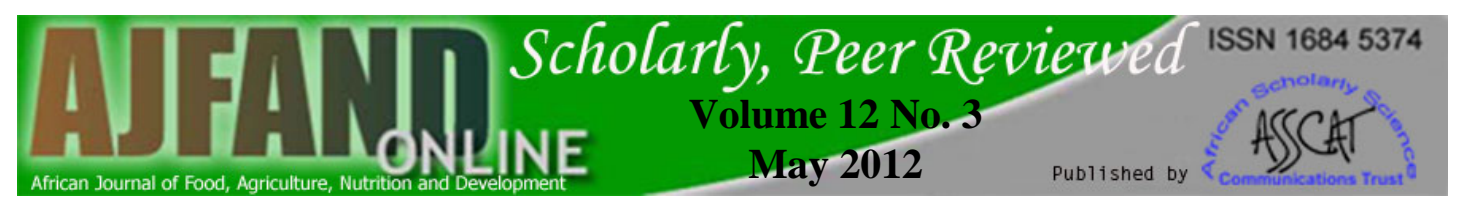

Table 1: Effect of isolated PGPRs (plant growth-promoting rhizobacterias) on maize root growth and IAA production in Gnotobiotic study (Growth Pouch Study)

\begin{tabular}{|c|c|c|c|c|c|}
\hline \multirow{2}{*}{ Bacterial Strains } & \multirow{2}{*}{$\begin{array}{c}\text { Experiment } \\
\text { Detail }\end{array}$} & \multicolumn{4}{|c|}{ Incubation Time (h) } \\
\hline & & 24 & 48 & 72 & 96 \\
\hline \multirow{2}{*}{ Control } & IAA Conc. (pmol/ml) & 0.15 & 0.99 & 1.51 & 2.43 \\
\hline & Root length (cm) & 0.10 & 0.40 & 1.10 & 2.00 \\
\hline \multirow{2}{*}{ AK1 } & IAA Conc. (pmol/ml) & 1.90 & 2.78 & 4.24 & 6.86 \\
\hline & Root length (cm) & 0.40 & 1.30 & 2.50 & 4.10 \\
\hline \multirow{2}{*}{ AK21 } & IAA Conc. (pmol/ml) & 2.00 & 2.88 & 4.40 & 7.11 \\
\hline & Root length (cm) & 0.42 & 1.35 & 2.59 & 5.00 \\
\hline \multirow{2}{*}{ AK11 } & IAA Conc. (pmol/ml) & 0.80 & 1.65 & 2.52 & 4.08 \\
\hline & Root length (cm) & 0.17 & 0.77 & 1.49 & 4.50 \\
\hline \multirow{2}{*}{ AK31 } & IAA Conc. (pmol/ml) & 2.00 & 2.88 & 4.40 & 7.11 \\
\hline & Root length (cm) & 0.42 & 1.35 & 2.59 & 5.00 \\
\hline \multirow{2}{*}{ AK8 } & IAA Conc. (pmol/ml) & 2.10 & 2.99 & 4.56 & 7.36 \\
\hline & Root length (cm) & 0.44 & 1.40 & 2.68 & 3.80 \\
\hline \multirow{2}{*}{ AK2 } & IAA Conc. (pmol/ml) & 1.10 & 1.96 & 2.99 & 4.83 \\
\hline & Root length (cm) & 0.23 & 0.92 & 1.76 & 4.00 \\
\hline \multirow{2}{*}{ AK30 } & IAA Conc. (pmol/ml) & 1.40 & 2.27 & 3.46 & 5.59 \\
\hline & Root length (cm) & 0.29 & 1.06 & 2.04 & 3.00 \\
\hline \multirow{2}{*}{ AK14 } & IAA Conc. (pmol/ml) & 1.00 & 1.86 & 2.84 & 4.58 \\
\hline & Root length (cm) & 0.21 & 0.87 & 1.67 & 5.20 \\
\hline AK19 & IAA Conc. (pmol/ml) & 0.90 & 1.76 & 2.68 & 4.33 \\
\hline
\end{tabular}




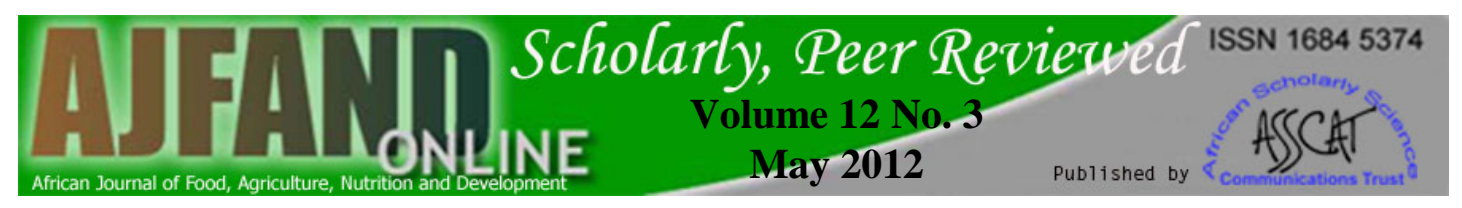

\begin{tabular}{|c|c|c|c|c|c|}
\hline & Root length (cm) & 0.19 & 0.82 & 1.58 & 5.00 \\
\hline \multirow{2}{*}{ AK17 } & IAA Conc. (pmol/ml) & 1.30 & 2.17 & 3.31 & 5.34 \\
\hline & Root length (cm) & 0.27 & 1.01 & 1.95 & 4.50 \\
\hline \multirow{2}{*}{ AK32 } & IAA Conc. (pmol/ml) & 1.50 & 2.37 & 3.62 & 5.85 \\
\hline & Root length (cm) & 0.32 & 1.11 & 2.13 & 5.30 \\
\hline \multirow{2}{*}{ AK3 } & IAA Conc. (pmol/ml) & 1.00 & 1.86 & 2.84 & 4.58 \\
\hline & Root length (cm) & 0.21 & 0.87 & 1.67 & 4.80 \\
\hline \multirow{2}{*}{ AK15 } & IAA Conc. (pmol/ml) & 0.90 & 1.76 & 2.68 & 4.33 \\
\hline & Root length (cm) & 0.19 & 0.82 & 1.58 & 3.30 \\
\hline \multirow{2}{*}{ AK9 } & IAA Conc. (pmol/ml) & 1.50 & 2.37 & 3.62 & 5.85 \\
\hline & Root length (cm) & 0.32 & 1.11 & 2.13 & 3.60 \\
\hline \multirow{2}{*}{ AK25 } & IAA Conc. (pmol/ml) & 1.90 & 2.78 & 4.24 & 6.86 \\
\hline & Root length (cm) & 0.40 & 1.30 & 2.50 & 4.80 \\
\hline
\end{tabular}


Table 2: Effect of isolated PGPRs (plant growth-promoting rhizobacterias) on wheat root growth and IAA production in Gnotobiotic study (Growth Pouch Study)

\begin{tabular}{|c|c|c|c|c|c|}
\hline \multirow{2}{*}{ Bacterial Strains } & \multirow{2}{*}{$\begin{array}{l}\text { Experiment } \\
\text { Detail }\end{array}$} & \multicolumn{4}{|c|}{ Incubation Time (h) } \\
\hline & & 24 & 48 & 72 & 96 \\
\hline \multirow{2}{*}{ Control } & IAA Conc. (pmol/ml) & 0.10 & 0.97 & 1.47 & 2.25 \\
\hline & Root length (cm) & 0.00 & 0.20 & 0.90 & 1.80 \\
\hline \multirow{2}{*}{ AK1 } & IAA Conc. (pmol/ml) & 0.60 & 1.63 & 2.49 & 3.80 \\
\hline & Root length (cm) & 0.20 & 0.70 & 1.70 & 3.50 \\
\hline \multirow{2}{*}{ AK21 } & IAA Conc. (pmol/ml) & 0.90 & 2.03 & 3.10 & 4.73 \\
\hline & Root length (cm) & 0.30 & 0.87 & 2.12 & 4.36 \\
\hline \multirow{2}{*}{ AK11 } & IAA Conc. (pmol/ml) & 0.30 & 1.23 & 1.88 & 2.87 \\
\hline & Root length (cm) & 0.10 & 0.53 & 1.28 & 2.64 \\
\hline \multirow{2}{*}{ AK31 } & IAA Conc. (pmol/ml) & 1.50 & 2.83 & 4.32 & 6.59 \\
\hline & Root length (cm) & 0.50 & 1.21 & 2.95 & 6.07 \\
\hline \multirow{2}{*}{ AK8 } & IAA Conc. (pmol/ml) & 1.00 & 2.17 & 3.31 & 5.04 \\
\hline & Root length (cm) & 0.33 & 0.93 & 2.26 & 3.60 \\
\hline \multirow{2}{*}{ AK2 } & IAA Conc. (pmol/ml) & 1.20 & 2.43 & 3.71 & 5.66 \\
\hline & Root length $(\mathrm{cm})$ & 0.40 & 1.04 & 2.53 & 4.00 \\
\hline \multirow{2}{*}{ AK30 } & IAA Conc. (pmol/ml) & 0.90 & 2.03 & 3.10 & 4.73 \\
\hline & Root length (cm) & 0.30 & 0.87 & 2.12 & 3.00 \\
\hline \multirow{2}{*}{ AK14 } & IAA Conc. (pmol/ml) & 1.10 & 2.30 & 3.51 & 5.35 \\
\hline & Root length (cm) & 0.37 & 0.99 & 2.39 & 5.20 \\
\hline AK19 & IAA Conc. (pmol/ml) & 1.00 & 2.17 & 3.31 & 5.04 \\
\hline
\end{tabular}




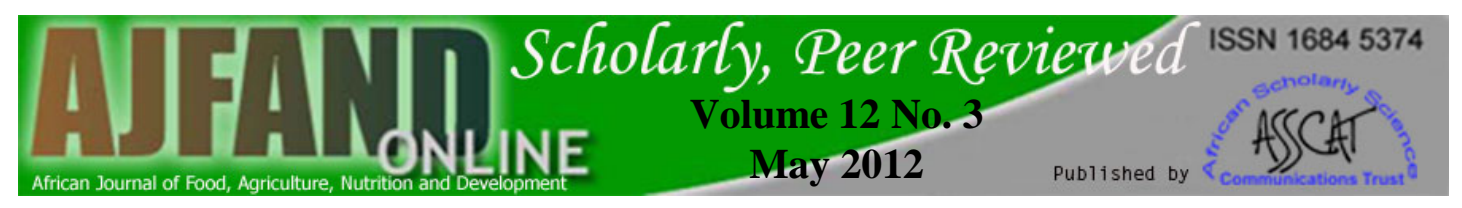

\begin{tabular}{|c|c|c|c|c|c|}
\hline & Root length (cm) & 0.33 & 0.93 & 2.26 & 4.60 \\
\hline \multirow{2}{*}{ AK17 } & IAA Conc. (pmol/ml) & 0.40 & 1.37 & 2.09 & 3.18 \\
\hline & Root length (cm) & 0.13 & 0.59 & 1.42 & 2.90 \\
\hline \multirow{2}{*}{ AK32 } & IAA Conc. (pmol/ml) & 1.80 & 3.23 & 4.93 & 7.53 \\
\hline & Root length (cm) & 0.60 & 1.39 & 3.37 & 6.90 \\
\hline \multirow{2}{*}{ AK3 } & IAA Conc. (pmol/ml) & 0.80 & 1.90 & 2.90 & 4.42 \\
\hline & Root length (cm) & 0.27 & 0.81 & 1.98 & 4.10 \\
\hline \multirow{2}{*}{ AK15 } & IAA Conc. (pmol/ml) & 1.20 & 2.43 & 3.71 & 5.66 \\
\hline & Root length (cm) & 0.40 & 1.04 & 2.53 & 5.20 \\
\hline \multirow{2}{*}{ AK9 } & IAA Conc. (pmol/ml) & 1.60 & 2.97 & 3.50 & 5.34 \\
\hline & Root length (cm) & 0.53 & 1.27 & 2.39 & 3.20 \\
\hline \multirow{2}{*}{ AK25 } & IAA Conc. (pmol/ml) & 1.20 & 2.43 & 3.71 & 5.66 \\
\hline & Root length (cm) & 0.40 & 1.04 & 2.53 & 4.80 \\
\hline
\end{tabular}




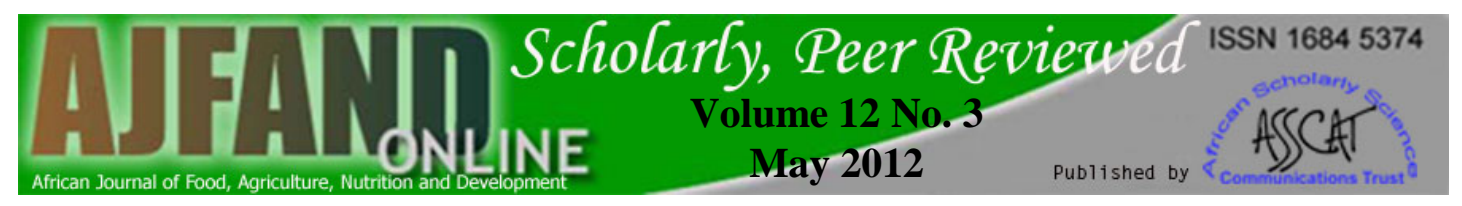

Table 3: Indole-3-acetic acid (IAA) production by isolated bacterial strains ( $\mu$ g $\mathrm{ml}^{-1}$ filtrate)

\begin{tabular}{|l|l|l|}
\hline Origin & Bacterial strains & IAA $\mathbf{\mu g} / \mathbf{m l}$ filtrate) \\
\hline Wheat rhizosphere & Bacillus lentus AK1 & 1.45 \\
\hline Wheat rhizosphere & Bacillus sp. AK21 & 1.90 \\
\hline Wheat rhizosphere & Azospirillum brasilense AK11 & 0.60 \\
\hline Wheat rhizosphere & Bacillus subtilis AK31 & 2.62 \\
\hline Wheat rhizosphere & Bacillus lentus AK8 & 1.36 \\
\hline Wheat rhizosphere & Bacillus sp. AK2 & 1.50 \\
\hline Wheat rhizosphere & Pseudomonas fluorescens AK30 & 1.30 \\
\hline Maize rhizosphere & Azotobacter diazotrophicus AK14 & 1.49 \\
\hline Maize rhizosphere & Microbacterium sp. AK19 & 1.30 \\
\hline Maize rhizosphere & Bacillus lentus AK17 & 1.11 \\
\hline Maize rhizosphere & Pseudomonas fluorescens AK32 & 2.70 \\
\hline Maize rhizosphere & Bacillus sp. AK3 & 1.40 \\
\hline Maize rhizosphere & Bacillus halodurans AK15 & 1.55 \\
\hline Maize rhizosphere & Pseudomonas AK9 & 1.50 \\
\hline Maize rhizosphere & Pseudomonas AK25 & \\
\hline
\end{tabular}


Table 4: Influence of isolated bacterial strains on shoot and root dry weight of maize and wheat

\begin{tabular}{|c|c|c|c|c|}
\hline \multirow[t]{2}{*}{ Bacterial strains } & \multicolumn{2}{|c|}{$\begin{array}{l}\text { Dry matter (g/pot) } \\
\text { of Maize }\end{array}$} & \multicolumn{2}{|c|}{$\begin{array}{c}\text { Dry matter (g/pot) } \\
\text { of Wheat }\end{array}$} \\
\hline & Root & Shoot & Root & Shoot \\
\hline Control & 100 & 100 & 100 & 100 \\
\hline & $(0.2021)$ & $(0.1623)$ & $(0.1956)$ & $(0.2205)$ \\
\hline Bacillus lentus AK1 & 110 & 101 & 120 & 105 \\
\hline Bacillus sp. AK21 & $123^{*}$ & 116 & $130 *$ & 105 \\
\hline Azospirillum brasilense AK11 & 115 & 110 & 106 & 100 \\
\hline Bacillus subtilis AK31 & $130 *$ & $126^{*}$ & $135^{*}$ & 106 \\
\hline Bacillus lentus AK8 & 110 & 101 & 116 & 108 \\
\hline Bacillus sp. AK2 & 116 & 108 & 120 & 101 \\
\hline Pseudomonas fluorescens AK30 & 104 & 100 & 109 & 100 \\
\hline Azotobacter diazotrophicus AK14 & 121 & $116^{*}$ & $125 *$ & $110 *$ \\
\hline Microbacterium sp. AK19 & 120 & 114 & 118 & 102 \\
\hline Bacillus lentus AK17 & 119 & 114 & 110 & 101 \\
\hline Pseudomonas fluorescens AK32 & $124^{*}$ & $120 *$ & $140 *$ & $110 *$ \\
\hline Bacillus sp. AK3 & 116 & 110 & 119 & 102 \\
\hline Bacillus halodurans AK15 & 109 & 101 & $123^{*}$ & 106 \\
\hline Pseudomonas AK9 & 109 & 101 & 115 & 101 \\
\hline Pseudomonas AK25 & 116 & 100 & 120 & 103 \\
\hline
\end{tabular}

* Significantly different from the control for $\mathrm{P}<0.05$ 


\section{REFERENCES}

1 Tripathi AK, Nagarajan T and SC Verma Inhibition of biosynthesis and activity of nitrogenase in Azospirillum brasilense Sp7 under salinity stress. Curr. Microbiol. 2002; 44:363-367.

2 Kloepper JW, Leong J, Teintze M and MN Scrhorth Enhanced plant growth by siderophores produced by plant growth promoting rhizobacteria. Nature 1980; 286:885-886.

3 Sylvia DM, Fuhrmann JJ, Hartel PG and DA Zuberer Principles and applications of soil microbiology. Prentice-Hall, Inc. Upper Saddle River, NJ, 1998:550.

$4 \quad$ Kloepper JW and CJ Beauchamp A review of issues related to measuring of plant roots by bacteria. Can. J. Microbiol. 1992; 8:1219-1232.

5 Glick BR, Karaturovi DM and PC Newell A novel procedure for rapid isolation of plant growth-promoting pseudomonads. Can. J. Microbiol. 1995; 41:533-536.

6 Glick BR, Patten CL, Holguin G and DM Penrose Biochemical and genetic mechanisms used by plant growth promoting bacteria. Imperial College Press, London, United Kingdom, 1999: 267.

7 Dunne C, Crowley JJ, Loccoz YM, Dowling DN, de Bruijn F and F O'Gara Biological control of Pythium ultimum by Stenotrophomonas maltophilia W81 is mediated by an extracellular proteolytic activity. Microbiology 1993; 143:3921- 3931.

8 Aslantas R, Cakmakci $\mathbf{R}$ and $\mathbf{F}$ Sahin Effect of plant growth promoting rhizobacteria on young apple tree growth and fruit yield under orchard conditions. Sci. Hort. 2007; 111: 371-377.

9 Allison LE Wet-combustion apparatus and procedure for organic and inorganic carbon in soil. Soil Sci. Sot. Am. Proc. 1960; 24:36-40.

10 Overman RR and AK Davis The Application of Flame Photometry to Sodium and Potassium Determinations in Biological Fluids. J. Biol. Chem. 1947; 641-649.

11 Zhongqi $\mathbf{H}$ and CW Honeycutt A Modified Molybdenum Blue Method for Orthophosphate Determination Suitable for Investigating Enzymatic Hydrolysis of Organic Phosphates. Comm.Soil. Sci. and Plant. Analy. 2005; 36:1373-1383.

12 Gordon SA and RP Weber Colorimetric estimation of indole acetic acid. Plant Physiol. 1951; 26:192-195.

13 Lifshitz R, Kloepper JW, Scher FM, Tipping EM and M Laliberté Nitrogenfixing pseudomonads isolated from the roots of plants grown in the Canadian high arctic. Appl. Environ. Microbiol. 1986; 51:251-255. 
14 Hoagland DR and TC Boyer General nature and process of salt accumulation by roots with description of experimental methods. Plant Physiol.1936; 11: 471-507.

15 Kampert M, Strzelczyk E and A Pokojska Production of auxins by bacteria isolated from the roots of pine seedlings (Pinus silvestris L.) and from soil. Pol. J. Microbiol. 1975; 7:135-143.

16 Patten CL and BR Glick Role of Pseudomonas putida indole acetic acid in development of the host plant root system. Appl. Environ. Microbiol. 2000; 68:37953801.

17 Fallik $\mathbf{E}$ and $\mathbf{Y}$ Okon Identification and quantification of IAA and IBA in Azospirillum brasilense inoculated maize roots. Soil Biol. Biochem. 1989; 21:147153.

18 Dobbelaere S, Croonenborghs A, Thys A, Ptacek D, Okon Y and J Vanderleyden Effect of inoculation with wild type Azospirillum brasilense and $A$. irakense strains on development and nitrogen uptake of spring wheat and grain maize. Biol. Fert. Soils.2002; 36(4):284-297.

19 Kozdroja J, Trevorsb JT and JD van Elsasc Influence of introduced potential biocontrol agents on maize seedling growth and bacterial community structure in the rhizosphere. Soil. Biol. Biochem.2004;36:1775-1784.

20 Shaharoona B, Arshad M, Zahir ZA and A Khalid Performance of Pseudomonas spp. containing ACC-deaminase for improving growth and yield of maize (Zea mays L.) in the presence of nitrogenous fertilizer. Soil. Biol. Biochem. 2006; 38: 2971-2975.

21 Pandy A, Sharma E and LKS Plani Influence of bacterial inoculation on maize in upland farming systems of the sikkim himalaya. Soil. Biol. Biochm. 1998; 30(3): 379-384.

22 Barbieri $\mathbf{P}$ and $\mathbf{E}$ Galli Effect on wheat root development of inoculation with an Azospirillum brasilense mutant with altered indole-3-acetic acid production. Res. Microbiol. 1993; 144:69-75.

23 Defreitas JR and JJ Germida Growth promotion of winter wheat fluorescent Pseudomonas under field conditions. Soil Biol. Biochem. 1992; 24:1137-1146.

24 Egamberdiyeva D and G Höflich Influence of growth promoting bacteria from Uzbekistan and Germany on the growth and nutrient uptake of cotton and wheat on different soils. In, Plant nutrition-Food security and sustainability of agro-ecosystems. W.J. Horst et al., (Eds), 2001: 674-675.

25 Prokryl Z, Vancura V and M Wurst Auxin formation by rhizosphere bacteria as a factor of root growth. Biol. Plant. 1985; 27:159- 163. 
26 Burd GI, Dixon DG and BR Glick Plant growth promoting rhizobacteria that decrease heavy metal toxicity in plants. Can.J.Microbiol.2000; 33:237-245.

27 Gravel V, Antoun $\mathbf{H}$ and $\mathbf{R J}$ Tweddell Growth stimulation and fruit yield improvement of greenhouse tomato plants by inoculation with Pseudomonas putida or Trichoderma atroviride: Possible role of indole acetic acid (IAA). Soil. Biol. Biochem. 2007; 39:1968-1977.

28 Abbass $\mathbf{Z}$ and $\mathbf{Y}$ Okon Plant growth promotion by Azotobacter paspali in the rhizosphere. Soil. Biol. Biochem.1993; 25 (8):1075-1083.

29 A Vikram Efficacy of phosphate solubilizing bacteria isolated from vertisols on growth and yield parameters of sorghum. Res. J. Microbiol. 2007; 2(7):550-559.

30 Dobbelaere S, Croonenborghs A, Thys A, Ptacek D, Vanderleyden J, Dutto P, Labendera-Gonzalez C, Caballero-Mellado J, Aguirre F, Kapulnik Y, Brener S, Burdman S, Kadouri D, Sarig S and Y Okon Response of Agronomically important crops to inoculation with Azospirillum. Aust. J. Plant. Physiol. 2001; 28:871-879. 